\title{
AVALIAÇÃO DOS PARÂMETROS DE LIBERAÇÃO PARA CONSUMO DE PALMITO DE PALMEIRA REAL (ROYSTONEA OLERACEA) EM CONSERVA ${ }^{1}$
}

\author{
Susana Irusta Mendez \\ Consultora autônoma, e-mail: susanairusta@yahoo.com.br \\ Andréa Clara Spoladore Damian \\ Consultora autônoma, e-mail: andreadamian@gmail.com
}

\begin{abstract}
RESUMO: Após o processamento do palmito em conserva, deve ser respeitado um período chamado de quarentena antes da sua liberação para consumo. Esse período é definido pela legislação em 15 dias, pois após esse período o produto não sofreria nenhum tipo de alteração e já estaria equalizado e estabilizado quanto ao seu pH. Porém, há indícios de que esse período definido na quarentena é insuficiente para a equalização do $\mathrm{pH}$ do palmito com o $\mathrm{pH}$ da salmoura, tornando o produto inseguro para o consumo, pois sabemos que em valores de $\mathrm{pH}$ acima de 4,5 pode haver $\mathrm{o}$ desenvolvimento de bactérias produtoras de toxinas como a toxina botulínica, sendo extremamente prejudicial à saúde. Diante disso, se faz necessária uma avaliação dos principais parâmetros de liberação para consumo de palmito em conserva definindo o período ideal de quarentena para liberação e consumo desse palmito. Os parâmetros analisados foram os seguintes: $\mathrm{pH}$, vácuo, turbidez da salmoura, coloração e indicação da presença da bactéria Clostridium. Ao todo foram utilizadas 102 amostras de palmito em toletes de palmeira real (Roystonea oleracea) em conserva.
\end{abstract}

Palavras-chave: Palmito em conserva. Quarentena. Segurança de alimentos.

1 Trabalho de Conclusão de Curso do MBA em Gestão para Segurança de Alimentos, SENAIsc. 


\section{INTRODUÇÃO}

O Brasil é o maior produtor e exportador mundial de palmito, especialmente para França e Estados Unidos. De acordo com a Associação Nacional dos Fabricantes de Palmito (ANFAP), a produção brasileira responde por $85 \%$ do mercado de exportação do palmito e $90 \%$ do consumo nacional. Somos o maior consumidor de palmito no mundo, o consumo é de 160 milhões de $\mathrm{kg}$ de palmito por ano, sendo o consumo per capita de palmito no Brasil de aproximadamente $940 \mathrm{~g} /$ pessoa/ano (ASSOCIAÇÃO NACIONAL DOS FABRICANTES DE PALMITO, 2006).

Diante de casos divulgados e analisados pela fiscalização da Vigilância Sanitária (WESTIN, 2008), com conseqüente apreensão de produtos e pela irresponsabilidade de determinados empresários, podemos verificar que produtos já dispostos para venda, muitas vezes se apresentam como insatisfatórios e inseguros para o consumo.

Em análises realizadas pela Vigilância Sanitária do estado de São Paulo, 65\% das amostras analisadas naquele estado, se apresentaram impróprias para o consumo, algumas das conservas analisadas apresentavam as condições necessárias para o desenvolvimento da bactéria transmissora do botulismo, uma doença que pode levar à morte (WESTIN, 2008).

Os esporos do Clostridium botulinum são resistentes ao calor e podem sobreviver em alimentos mínima ou incorretamente processados, onde podem germinar (dependendo das condições) e se multiplicar, deteriorando os alimentos ou causando doenças de origem alimentar (SCOTT; MOBERG, 1995 apud MAGNANI et al, 2008).

O botulismo de origem alimentar é um tipo grave de intoxicação causada pela ingestão de alimentos que contêm a neurotoxina formada durante o desenvolvimento do Clostridium botulinum. A toxina é termolábil e pode ser destruída, se aquecida a $80^{\circ} \mathrm{C}$, por dez minutos. Uma quantidade muito pequena da toxina (alguns nanogramas) já pode causar a doença (FDA, 1992 apud MAGNANI et al, 2008).

Esse tipo de botulismo ocorre poringestão de toxinas presentes em alimentos previamente contaminados e que foram produzidos ou conservados de maneira inadequada. Os alimentos mais comumente envolvidos são: conservas vegetais, principalmente as artesanais (palmito, picles, pequi); produtos cárneos cozidos, curados e defumados de forma artesanal (salsicha, presunto, carne frita conservada em gordura - "carne de lata"); pescados defumados, salgados e fermentados; queijos e pasta de queijos e, raramente, em alimentos enlatados industrializados (BRASIL, 2008).

Entre 1999 e setembro de 2008, foram registrados no Brasil 105 casos suspeitos de botulismo, sendo 39 confirmados, dos quais 37 casos foram do tipo alimentar, um caso por ferimento e um caso intestinal. Dos casos confirmados, houve dezenove óbitos. A maioria desses casos, segundo o Ministério da Saúde, teve origem nos alimentos em conserva. Do total dos casos, pode-se afirmar que $11 \%$ foram provenientes de palmito em conserva (BRASIL, 2008). 
Conforme a legislação, as indústrias não podem liberar o produto por um período de quinze dias após sua fabricação, período esse chamado de quarentena. É durante esse período que podem ser observadas diversas alterações, que ocasionalmente podem ocorrer nas conservas de palmito, como reações oxidativas, alterações de cor, turbidez na salmoura, variações de $\mathrm{pH}$, falhas na pasteurização, defeitos no fechamento, subcozimento, entre outras.

A variação do $\mathrm{pH}$ é o parâmetro mais crítico, pois sabemos que valores de $\mathrm{pH}$ acima de 4,5 podem propiciar o desenvolvimento de bactérias deteriorantes e/ou produtoras de toxinas como a toxina botulínica, sendo extremamente prejudicial à saúde.

\subsection{Objetivo geral}

Definir o período ideal de quarentena para liberação dos lotes de palmito em conserva.

\subsection{Objetivos específicos}

a) Estabelecer parâmetros precisos de liberação de lotes de palmito em conserva.

b) Avaliar os parâmetros de liberação para consumo de lotes de palmito em conserva.

c) Definir o período exato em que o Ph da conserva de palmito (salmoura + palmito) está equalizado e estável;

d) Analisar as variações dentro de um mesmo lote;

e) Definir o período a partir do qual não haverá alteração no aspecto visual da conserva (turbidez e coloração) antes da liberação para consumo;

f) Identificar o intervalo máximo dentro do qual ainda pode aparecer defeitos no fechamento e perda de vácuo das embalagens.

\section{PROCEDIMENTOS METODOLÓGICOS}

O estudo foi realizado em uma indústria fabricante de Palmito em Conserva situada na região da Grande Florianópolis. Toda a matéria-prima utilizada para o preparo das conservas em avaliação foi proveniente da espécie de Palmeira Real (Roystonea Oleracea) da família Palmae. Nessa indústria, são fabricados 4 tipos de cortes de palmito, sendo eles: tolete, rodela, banda e picado. Para o estudo em questão, foi escolhido o palmito em conserva tolete, envasado em vidros com $550 \mathrm{~g}$ de peso líquido e com peso drenado de $300 \mathrm{~g}$. Acredita-se que o palmito cortado em toletes leva mais tempo para equilibrar o pH da salmoura com o palmito em comparação aos demais cortes. O tolete é um corte mais tenro, denso e de maior espessura e comprimento. 
A coleta das amostras foi realizada através de amostragem probabilística aleatória simples. A partir do mês de abril de 2009, foram coletadas ao mesmo tempo 17 amostras por mês, sendo todas da mesma data de produção e do mesmo lote. Esta coleta foi repetida durante 6 meses, totalizando 102 unidades amostrais durante toda a pesquisa.

As amostras coletadas a cada mês foram todas do mesmo lote com objetivo de verificar as possíveis variações do produto no decorrer de 30 dias.

Todas as amostras coletadas foram fabricadas sob as mesmas condições de processamento (tempo e temperatura de cozimento, percentual de palmito $\mathrm{x}$ salmoura por embalagem e condições de armazenamento e estocagem). As amostras em análise foram mantidas no laboratório de controle de qualidade da empresa em temperatura ambiente e em local seco e arejado com o objetivo de evitar que alguma outra condição pudesse vir a interferir nos resultados do estudo.

A seguir, estão listados os parâmetros analisados e coletados durante a pesquisa:

- $\mathrm{pH}$;

- vácuo;

- turbidez da salmoura;

- coloração (oxidação aparente) e

- clostrídio sulfitos redutores.

Os valores de $\mathrm{pH}$ foram medidos através do método potenciométrico no homogeneizado segundo normas do Instituto Adolfo Lutz (1985).

O método potenciométrico baseia-se na medida do potencial de células eletroquímicas na ausência de correntes. Envolve a utilização de equipamentos simples e pouco dispendiosos: eletrodo de referência (ânodo), eletrodo indicador (cátodo) e potenciômetro. O eletrodo indicador é seletivo para um determinado íon, tornando possível a obtenção da concentração desse íon através do valor do potencial medido.

O phmetro utilizado foi previamente calibrado com solução tampão. Os valores de $\mathrm{pH}$ medidos foram realizados diretamente no homogeneizado, que foi preparado da seguinte forma: O conteúdo de palmito do vidro foi homogeneizado com água destilada na proporção de 1:2 e nesse conteúdo foi inserido o eletrodo e realizada a leitura do $\mathrm{pH}$.

A medição do vácuo foi realizada conforme Manual Técnico $\mathrm{n}^{\circ} 15$ do Instituto de Tecnologia de Alimentos (1990). 
Para a medição do vácuo foi utilizado um vacuômetro que mede em polegadas de mercúrio. O procedimento foi o seguinte: umedecer ligeiramente a tampa do recipiente, comprimir firmemente o vacuômetro na tampa em um ponto qualquer próximo da borda, perfurando-a. Proceder a leitura da reflexão da agulha.

Para a avaliação da coloração do palmito e da turbidez da salmoura, que foram realizadas visualmente, foi estipulada uma escala já que não existe um parâmetro de comparação pré-definido. Para a avaliação da coloração do palmito foi estipulada uma escala com três numerações: número 1 para coloração normal (branca), número 2 para coloração levemente amarelada / oxidado e número 3 para coloração levemente rósea. Para a avaliação da turbidez da salmoura também foi estipulada uma escala com três numerações, são elas: número 1 para uma turbidez normal (translúcida), número 2 para turbidez ligeiramente esbranquiçada e número 3 para turbidez esbranquiçada

A metodologia utilizada para análise de clostrídio sulfitos redutores foi a do Compendium of Methods of the Microbiological Examination of Foods (AMERICAN PUBLIC HEALTH ASSOCIATION, 2001).

As análises do $\mathrm{pH}$, vácuo, turbidez e coloração, foram realizadas a cada dois dias e a análise de clostrídio sulfitos redutores foi analisada uma vez ao mês, salientando que a amostra para a análise microbiológica todas as vezes foi retirada do mesmo lote que estava em análise naquele determinado mês. Esse procedimento foi repetido no período de 6 meses.

\section{RESULTADOS}

Com o objetivo de definir o período de quarentena para liberação dos lotes de palmito em conserva, os seguintes parâmetros foram coletados e analisados: vácuo (medido em polegadas de mercúrio, pol Hg), pH do palmito em conserva, turbidez da salmoura utilizada nas conservas, coloração do palmito em conserva e análise de clostrídio sulfitos redutores no palmito em conserva.

\subsection{Informações previamente coletadas}

Antes do início da produção do palmito em conserva analisado, algumas informações se mostraram necessárias para a definição da composição da salmoura. A primeira informação a ser medida foi o pH da palmeira a ser processada, que normalmente se apresenta entre os valores de 5,6 e 6,2 conforme o lote a ser industrializado. Essa informação interfere diretamente na quantidade de ácido a ser utilizado no preparo da salmoura da conserva e conseqüentemente no $\mathrm{pH}$ da salmoura e no $\mathrm{pH}$ de equilíbrio do palmito com a salmoura. 


\begin{tabular}{|c|c|c|c|c|c|c|}
\hline $\begin{array}{c}\text { Item } \\
\text { avaliado }\end{array}$ & Abril & Maio & Junho & Julho & Agosto & Setembro \\
$\begin{array}{c}\text { Ph do } \\
\text { palmito in } \\
\text { natura }\end{array}$ & 5,98 & 6,07 & 6,00 & 6,05 & 6,09 & 6,01 \\
$\begin{array}{c}\text { Ph da } \\
\text { salmoura }\end{array}$ & 2,11 & 2,12 & 2,12 & 2,11 & 2,12 & 2,11 \\
$\begin{array}{c}\text { Ph de } \\
\text { equilíbrio } \\
\text { da conserva } \\
\text { (palmito + } \\
\text { salmoura) }\end{array}$ & 4,19 & 4,19 & 4,20 & 4,18 & 4,19 & 4,19 \\
$\begin{array}{c}\text { Percentual } \\
\text { de ácido na } \\
\text { salmoura }\end{array}$ & 0,750 & 0,775 & 0,750 & 0,750 & 0,775 & 0,750 \\
\hline $\begin{array}{c}\text { Percentual } \\
\text { de sal na } \\
\text { salmoura }\end{array}$ & 3,0 & 3,0 & 3,0 & 3,0 & 3,0 & 3,0 \\
\hline
\end{tabular}

Quadro 1 - Avaliação mensal do pH da palmeira, da salmoura, da conserva e dos percentuais de ácido e sal na salmoura no dia zero.

Fonte: Dos Autores

As informações previamente coletadas nos lotes analisados, praticamente se apresentaram constantes para os seis lotes, apresentando uma variação muito pequena. Devido à homogeneidade dos lotes analisados durante esses meses, essas informações não interferiram nas medições realizadas no decorrer da pesquisa.

\subsection{Análise de PH}

Gráfico1 - Comportamento do pH nos meses (abril a setembro)

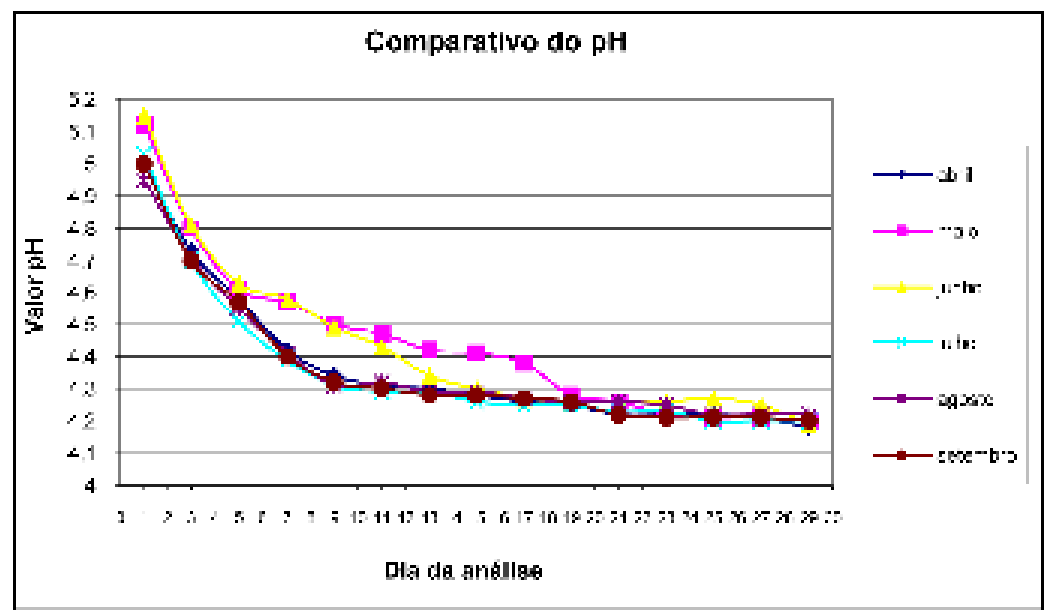

Fonte: dos autores. 
Ao longo dos seis meses de coleta dos dados, foi verificado que a estabilidade ocorreu por volta do 210 dia após a fabricação do palmito em conserva, permanecendo o valor do $\mathrm{pH}$ em 4,2. Este valor já é considerado seguro para o alimento, pois não há mais risco de que ocorra o crescimento da bactéria Clostridium. A estabilidade do $\mathrm{pH}$ aqui medido ultrapassou o período da quarentena definido em 15 dias, porém, independente disso, percebemos que no 150 dia o pH já se encontrava abaixo de 4,5 valor a partir do qual não pode mais haver o crescimento da bactéria.

\subsection{Análise de vácuo}

Gráfico2 - Variação do vácuo nos meses (abril a setembro)

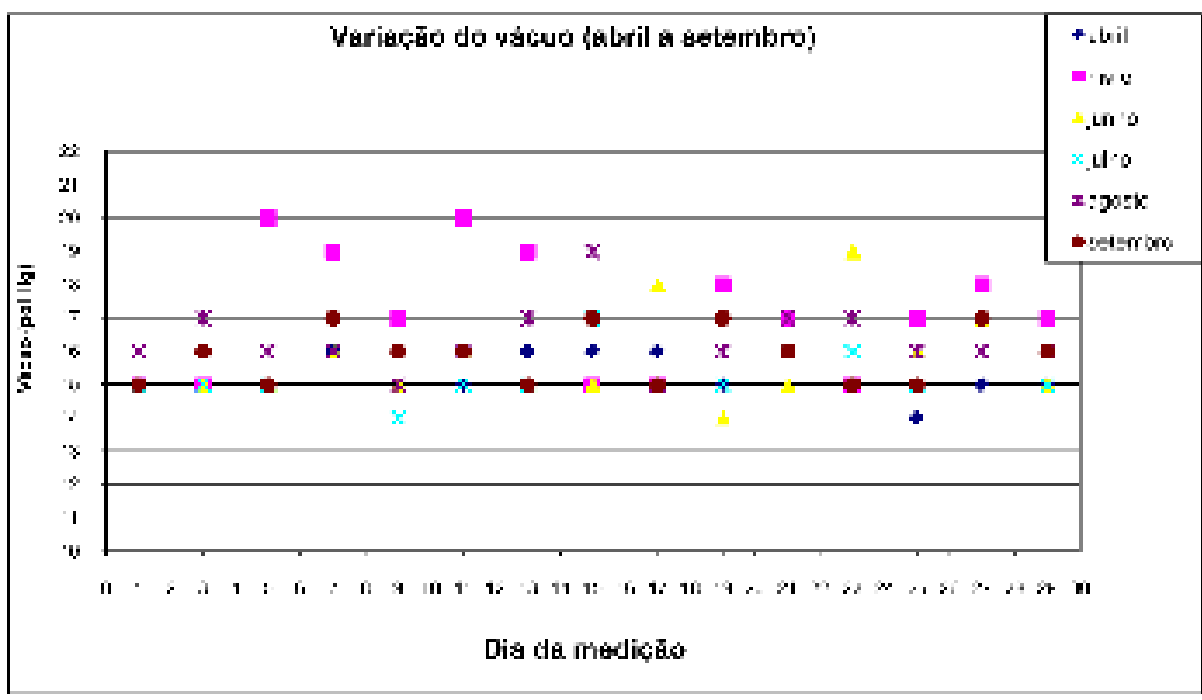

Fonte: dos autores

Pode-se verificar que em nenhuma das amostras analisadas durante os seis meses houve a perda de vácuo no período de 30 dias e nem mesmo foram observados defeitos no fechamento das embalagens.

O vácuo da embalagem é um indicador das condições de conservação do produto. Um vácuo baixo reduz sensivelmente a vida-de-prateleira do produto por favorecer a corrosão interna das tampas e a oxidação do produto.

O que pôde ser observado, foi que nos meses de abril, junho e julho, houve três amostras, uma em cada mês, que apresentaram o valor do vácuo em 14 polegadas de $\mathrm{Hg}$, sendo este valor abaixo do valor mínimo estipulado pela legislação que é de 15 polegada de $\mathrm{Hg}$.

As variações oscilaram de 14 pol Hg até o máximo de 20 pol Hg. Não há um valor máximo estipulado.

Através dos valores obtidos e pela análise dos gráficos, verificamos que não há um intervalo para ocorrência da perda do vácuo nos vidros, desde que estes tenham sido bem fechados no momento do envase e que o cozimento tenha sido feito de maneira correta, portanto, não há necessidade de quarentena para a segurança desse requisito. 


\subsection{Análise da turbidez da salmoura}

Gráfico3 - Variação da turbidez nos meses (abril a setembro)

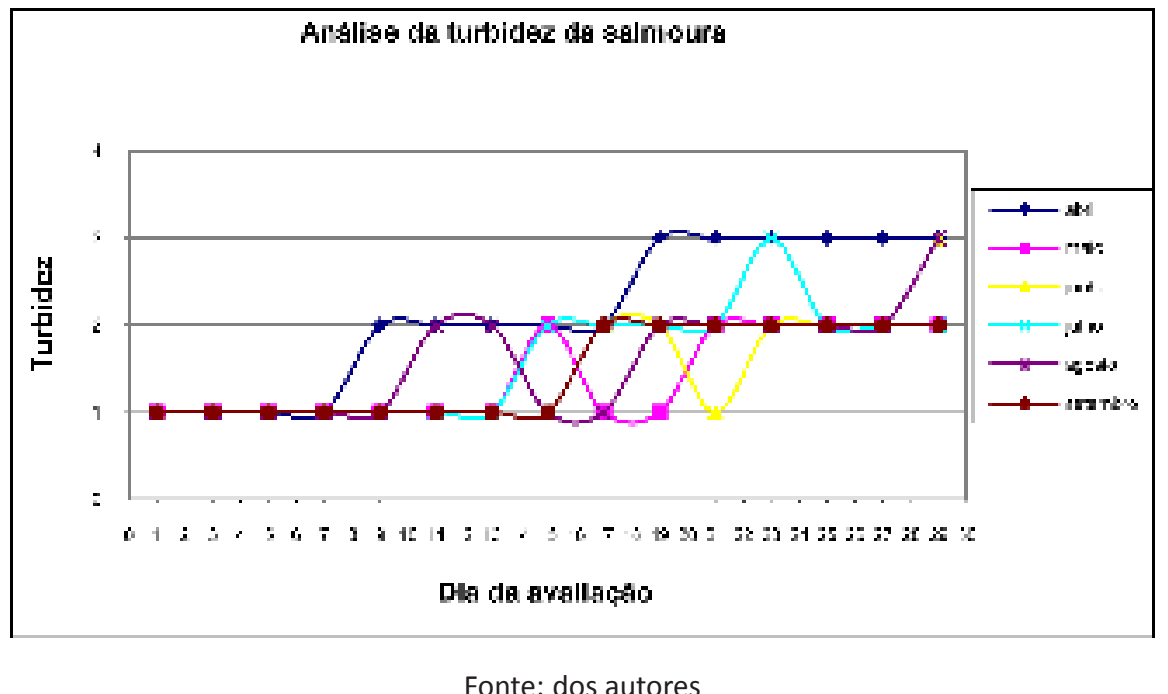

Fonte: dos autores

Ao analisar os valores e os gráficos referentes a turbidez da salmoura, pode-se verificar que entre os dias 17 e 19, não ocorreram muitas variações relacionadas a turbidez da salmoura, mas ocorreram alguns pontos isolados gerando turbidez esbranquiçada. Esse fato pode ser considerado normal por se tratar do palmito extraído da espécie de Palmeira Real, aspecto que não deprecia o produto.

\subsection{Análise da coloração do palmito}

A coloração do palmito em conserva foi avaliada visualmente e foi percebido que não houve nenhuma alteração relacionada a esse aspecto no decorrer do período das avaliações. A cor branca, característica do palmito de palmeira real em conserva, se manteve completamente inalterada desde o primeiro dia até o último dia da avaliação. Isso se repetiu no decorrer dos seis meses de avaliação.

Através da avaliação da coloração dos palmitos em conserva, pode se verificar que não há um intervalo para ocorrência da alteração da cor durante o período avaliado. Provavelmente não houve nenhuma alteração devido aos controles realizados durante seu processamento, não havendo necessidade de quarentena para avaliação desse requisito.

\subsection{Análise de clostrídio sulfitos redutores}

O objetivo da realização dessa análise no palmito em conserva foi a de oferecer uma indicação rápida do potencial da presença de Clostridium perfringens e Clostridium botulinum, espécies capazes de causar Doenças Transmitidas por Alimentos. 
Segundo laudos emitidos pelo Laboratório de Tecnologia de Alimentos da Universidade Federal de Santa Catarina, os valores obtidos das análises referentes à clostrídios sulfitos redutores foram os seguintes:

\begin{tabular}{|c|c|c|c|c|c|c|}
\hline Dia & Abril & Maio & Junho & Julho & Agosto & Setembro \\
\hline 29 & $<1,0 \times 10^{1}$ & $<1,0 \times 10^{1}$ & $<1,0 \times 10^{1}$ & $<1,0 \times 10^{1}$ & $<1,0 \times 10^{1}$ & $<1,0 \times 10^{1}$ \\
\hline
\end{tabular}

Quadro 2 - Resultados da análise de clostrídio sulfitos redutores.

Fonte: dos autores

Em nenhuma das amostras analisadas no laboratório houve a indicação da presença do Clostridium. Vale salientar que a produção do palmito em análise seguiu todas as normas de Boas Práticas de Fabricação, bem como todas as legislações pertinentes ao Palmito em Conserva, fatores que contribuíram para os bons resultados obtidos na análise de clostrídio sulfitos redutores.

$\mathrm{Na}$ análise do $\mathrm{pH}$ do palmito em conserva, no decorrer dos trinta dias analisados em cada lote, não se pode afirmar precisamente o dia exato em que este se encontrou totalmente estável, pois houve lotes que a partir do $19^{\circ}$ dia já se apresentavam estáveis e houveram lotes em que a estabilidade ocorreu somente no $25^{\circ}$ dia. Nas amostras analisadas, a estabilidade ocorreu quando o palmito atingiu um valor de $\mathrm{pH}$ de aproximadamente 4,2.

A estabilidade do $\mathrm{pH}$ aqui medido neste trabalho ultrapassou o período da quarentena definido em 15 dias, havendo ainda variações após esse período, porém, independente disso, no $15^{\circ}$ dia o $\mathrm{pH}$ já se encontrava em patamar seguro, não podendo mais haver $\mathrm{o}$ crescimento da bactéria Clostridium.

$\mathrm{Na}$ análise do vácuo, pode-se concluir que o período de quarentena não interfere na variação do mesmo. O que podemos observar é que existiram três amostras com um valor considerado baixo, 14 polHg, sendo que o mínimo definido na legislação é de 15 polHg. É provável que tal fato tenha ocorrido em função do fechamento hermético dos vidros realizado de forma inadequada.

$\mathrm{Na}$ análise da turbidez da salmoura das conservas, pode-se notar que a estabilização da mesma variou de um lote para outro, ocorrendo em alguns lotes no $15^{\circ}$ dia até o $21^{\circ}$ dia. Diante disso, não é possível afirmar precisamente o dia exato em que a turbidez atinge a estabilidade. Uma leve turbidez pode ser considerada normal nas conservas de palmito elaboradas a partir da palmeira real, ou seja, o parâmetro em questão não deprecia o palmito dessa espécie.

Quanto à coloração do palmito em análise, não foi percebida nenhuma alteração visível no decorrer dos 30 dias verificados em nenhum dos lotes em análise. 
Quanto aos resultados das análises de clostrídio sulfitos redutores, todos se mostraram satisfatórios, não indicando a presença da bactéria Clostridium em nenhum dos lotes analisados.

Diante de todos os parâmetros analisados, pode-se concluir que a definição do período de quarentena é importante a fim de garantir que o $\mathrm{pH}$ da conserva se encontre em um valor seguro, abaixo de 4,5, no momento do consumo. Neste caso 15 dias seriam suficientes. Quanto a estabilidade da turbidez, 15 dias pode ser considerado um período curto, pois a mesma ainda se encontra variando.

Os demais parâmetros analisados, o vácuo, a coloração e a análise de clostrídio sulfitos redutores, independem do período de quarentena. Concluímos que não há um intervalo para ocorrência da perda do vácuo nos vidros, alteração na coloração e presença da toxina do Clostridium desde que estes tenham sido bem fechados no momento do envase, que o cozimento tenha sido feito de maneira correta e que todos os controles necessários estejam devidamente implantados. Portanto, não há necessidade de quarentena para a segurança desses três parâmetros.

\section{CONCLUSÃO}

Os parâmetros aqui abordados destacaram a importância da realização do estudo para o conhecimento das variações ocorridas após o processo de fabricação e que podem interferir na segurança do alimento em questão. Diante desse estudo, podemos perceber a importância da implantação das Boas Práticas de Fabricação para a produção das conservas de palmito em conserva. A maioria desses parâmetros pode garantir por si só a elaboração de um alimento seguro se as normas e procedimentos forem seguidos de maneira adequada e consciente. 


\title{
EVALUATION OF THE PARAMETERS FOR RELEASE FOR CONSUMPTION OF CANNED PALM FROM ROYAL PALM TREE (ROYSTONEA OLERACEA)
}

\begin{abstract}
After the processing of palm canned, should be an interval called quarantine before their release for consumption. This period is set by law in 15 days, since after this period the product would not suffer any kind of change and it would be equalized and stabilized as its $\mathrm{pH}$. However, there is evidence that the quarantine period set is insufficient to equalize the $\mathrm{pH}$ of the palm with the $\mathrm{pH}$ of the brine, making the product unsafe for consumption, because we know that at $\mathrm{pH}$ above 4.5 can be no development bacteria producing toxins such as botulinum toxin, is highly detrimental to health. Given this, it is necessary to evaluate the main parameters of release for consumption of palm canned defining the ideal period for quarantine release and consumption this palm. The parameters analyzed were as follows: $\mathrm{pH}$, vacuum, brine turbidity, color and indication of the presence of the bacterium Clostridium. Altogether 102 samples were used for cuttings in canned royal palm tree (Roystonea oleracea).
\end{abstract}

Keywords: Canned palm. Quarantine. Food safety.

\section{REFERÊNCIAS}

AMERICAN PUBLIC HEALTH ASSOCIATION. Compendium of methods of the microbiological examination of foods. 4.ed. Washington: APHA, 2001.

ASSOCIAÇÃO NACIONAL DOS FABRICANTES DE PALMITO. Palmito: Resgate da confiança. 2006. Disponível em: <http://www.agr.feis.unesp.br/selo_palmito.htm> . Acesso em: 31 out. 2011.

BRASIL. Ministério da Saúde. Guia de vigilância epidemiológica. 6 ed. Brasília, DF: Secretaria de Vigilância em Saúde, 2008. Disponível em <http://bvsms.saude.gov.br/ bvs/publicacoes>. Acesso em: 28 out. 2011.

INSTITUTO ADOLFO LUTZ. Normas Analíticas do Instituto Adolfo Lutz: métodos químicos e físicos para análise de alimentos. $3^{\text {a }}$ ed. vol. 1, São Paulo, 1985.

INSTITUTO DE TECNOLOGIA DE ALIMENTOS. Metodologia de Análise Microbiólogica de Alimentos: Manual técnico no 15. Campinas: ITAL, 1990.

MAGNANI, A. L. et. al. Fundamentos para a análise de perigos e riscos. $2^{\mathrm{a}}$ ed., p.98, Florianópolis: SENAI/SC, 2008.

WESTIN, Ricardo. Vigilância reprova 65\% de amostras de palmito em conserva. 2008. Disponível em: <http://www1.folha.uol.com.br/folha/cotidiano/ult95u446616.

shtml>. Acesso em: 28 out. 2011. 


\section{SOBRE O(S) AUTOR(ES)}

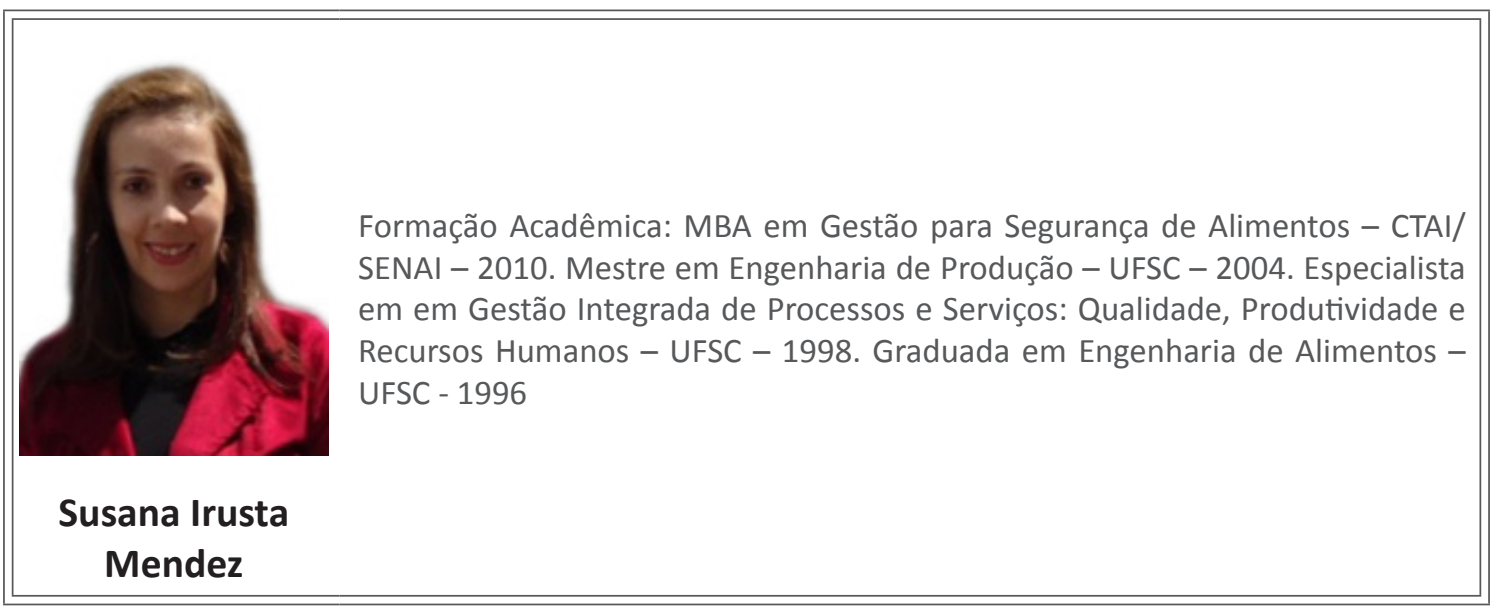

Mestre em Ciência dos Alimentos (UFSC). Graduada em Farmácia Bioquímica de
Alimentos(UFSC). Graduada em Pedagogia (UNISUL). Consultora em segurança
de alimentos.Professora Tutora dos cursos de MBA Gestão para a Segurança
de Alimentos e Gestão para Excelência no SENAI-Florianópolis de 2007 a 2011.
Damian

